\title{
White Coat Hypertension in Definition of Metabolic Syndrome
}

\author{
Mehmet Rami Helvaci, ${ }^{1}$ MD, Hasan KayA, ${ }^{1}$ MD, Mahmut SEYhanli, ${ }^{2}$ MD, \\ and Atilla YALCIN, ${ }^{2} \mathrm{MD}$
}

\begin{abstract}
SUMMARY
Although white coat hypertension (WCH) is believed to have an effect on health, there is no term defining $\mathrm{WCH}$ in metabolic syndrome.

Consecutive patients 20 years old or older who underwent a check-up were included. The study included 1068 cases. The prevalences of hyperbetalipoproteinemia, hypertriglyceridemia, dyslipidemia, impaired glucose tolerance (IGT), and WCH were similar to excess weight in that they increased significantly until the seventh decade of life and decreased thereafter significantly $(P<0.05$ in most steps). On the other hand, the prevalences of hypertension (HT), diabetes mellitus (DM), and coronary heart disease (CHD) always increased significantly with age without any decrease $(P<0.05$ in most steps), indicating their irreversibility in contrast to the reversibility of excess weight, hyperbetalipoproteinemia, hypertriglyceridemia, dyslipidemia, IGT, and $\mathrm{WCH}$.

Metabolic syndrome is a reversible progression step between health and irreversible final diseases terminating with increased mortality and disabilities. Thus, the definition of metabolic syndrome should include reversible metabolic risk factors such as excess weight (overweight and obesity), hyperbetalipoproteinemia, hypertriglyceridemia, dyslipidemia, IGT, and WCH, instead of irrevesible diseases such as DM, HT, CHD, and stroke that have already developed and require drug therapy. After development of one of the final metabolic diseases, the term metabolic syndrome probably loses most of its significance, since from that point on, nonpharmaceutical approaches such as lifestyle changes, diet, and exercise will provide little benefit to prevent development of the others, most likely due to the cumulative effects of the risk factors on body systems over a long period of time. (Int Heart J 2008; 49: 449-457)
\end{abstract}

Key words: White coat hypertension, Metabolic syndrome, Excess weight, Dyslipidemia, Impaired glucose tolerance

AN association between certain metabolic parameters and hypertension (HT), type 2 diabetes mellitus (DM), coronary heart disease (CHD), stroke, and eventually an increased all-cause mortality has been known for many years and is

\footnotetext{
From the ${ }^{1}$ Medical Faculty of the Mustafa Kemal University, Antakya, and ${ }^{2}$ Medical Faculty of the Mersin University, Mersin, Turkey. 
defined as metabolic syndrome. ${ }^{1,2)}$ Metabolic syndrome is characterized by a group of metabolic risk factors, including obesity, dyslipidemia, elevated blood pressure (BP), insulin resistance, and a prothrombotic and proinflammatory state, ${ }^{3)}$ and is not a specific disease since it can be reversed completely with appropriate nonpharmaceutical approaches including lifestyle changes, diet, and exercise. ${ }^{4)}$ Therefore, it actually includes risk factors for the development of irreversible final diseases which decrease the duration and/or quality of normal life such as HT, DM, CHD, and stroke. Metabolic syndrome has become increasingly common in developed countries; for example, it is estimated that 50 million Americans have it. ${ }^{5)}$ On the other hand, white coat hypertension (WCH) is a wellknown clinical entity defined as a persistently elevated BP in the doctor's office whereas normal in other conditions. It was reported in the Ohasama study ${ }^{6}$ that WCH is a risk factor for development of home HT. Similarly, intima-media thickness and cross-sectional area of the carotid artery were found to be similar in patients with WCH and HT, which were significantly higher than in cases with sustained normotension (NT). ${ }^{7)}$ Additionally, plasma homocysteine levels were higher, and left ventricle mass index was greater in the WCH group compared to NT cases $(P<0.001$ in both), but they were significantly lower in the WCH group than HT cases in another study $\left(P<0.001\right.$ and $P=0.005$, respectively) ${ }^{8}{ }^{8}$ Although it is highly suspected that $\mathrm{WCH}$ has clinical significance for human health, there is no term defining $\mathrm{WCH}$ in metabolic syndrome. In the present study, we have attempted to determine the position of $\mathrm{WCH}$ in the definition of metabolic syndrome.

\section{Methods}

The study was performed at the Internal Medicine Polyclinic of Dumlupinar University between August 2005 and March 2007. Consecutive patients 20 or older applying for a medical check-up were enrolled. Their medical histories including smoking habit, DM, dyslipidemia, and current medications were taken, and routine tests such as fasting plasma glucose (FPG), triglycerides (TG ), high density lipoprotein cholesterol (HDL-C), low density lipoprotein cholesterol (LDL-C), and electrocardiography were performed. Current regular smokers, defined as those who had smoked for at least for the last 6 months, and cases with a previous smoking history of at least 5 pack-years were classified as smokers. Cigar or pipe smokers were excluded. Patients with devastating illnesses including type $1 \mathrm{DM}$, malignancies, acute and chronic renal failure, chronic liver diseases, hyper- or hypothyroidism, and heart failure were excluded to avoid their possible effects on weight. The body mass index (BMI) of each case was calculated based on measurements taken by the physician. Weight in kilograms was 
divided by height in meters squared. Underweight was defined as a BMI below 18.5, normal weight as 18.5-24.9, overweight as 25-29.9, and obesity as a BMI of $30.0 \mathrm{~kg} / \mathrm{m}^{2)}$ or greater. ${ }^{9)}$ Cases with an overnight FPG level of $126 \mathrm{mg} / \mathrm{dL}$ or greater on two occasions or already taking antidiabetic medications were defined as diabetics. An oral glucose tolerance test with 75-gram glucose was performed in cases with a FPG level between 110 and $126 \mathrm{mg} / \mathrm{dL}$, and cases with a 2-hour plasma glucose level of $200 \mathrm{mg} / \mathrm{dL}$ or higher were diagnosed with DM while 140-199 mg/dL was considered to indicate impaired glucose tolerance (IGT). Patients with dyslipidemia were identified and dyslipidemic subgroups were defined using the National Cholesterol Education Program Expert Panel's recommendations. ${ }^{9)}$ Dyslipidemia was diagnosed when LDL-C was 160 or higher and/ or TG were 200 or higher and/or HDL-C was lower than $40 \mathrm{mg} / \mathrm{dL}$. Stress electrocardiography was performed in cases with a history of angina pectoris or suspected of having angina perctoris on electrocardiography, and coronary angiography was only performed in stress electrocardiography positive cases. Thus, CHD was diagnosed either angiographically or based on a history of coronary artery bypass graft surgery. Office blood pressure (OBP) was checked after a 5-minute rest in a seated position with a mercury sphygmomanometer on 3 visits, and no smoking was permitted during the 2 preceeding hours. Home blood pressure (HBP) was measured twice daily for 10 days in all cases, even in normotensives in the office due to the risk of masked HT, after a 10-minute explanation about proper BP measurement techniques. ${ }^{10)}$ The patients were advised to perform upper arm measurements using a standard adult cuff with bladder sizes of 12 $\times 26 \mathrm{~cm}$ for arm circumferences up to $33 \mathrm{~cm}$ in length, and a large adult cuff with bladder sizes of $12 \times 40 \mathrm{~cm}$ for arm circumferences up to $50 \mathrm{~cm}$ in length. They were also advised to rest for at least 5 minutes in the seated position before taking a measurement. The use of wrist and finger devices was discouraged. An additional 24-hour ambulatory blood pressure monitoring (ABP) was obtained only in cases with a higher OBP and/or HBP measurements and was performed with oscillometrical equipment (SpaceLabs 90207, Redmond, Washington, USA) set to take a reading every 10 minutes throughout a 24 -hour period. Normal daily activities were allowed and the subjects were asked to keep the arm as relaxed as possible during measurements. HT is defined as a BP of $135 / 85 \mathrm{mmHg}$ or greater during the daytime (between $10 \mathrm{AM}$ to $8 \mathrm{PM}$ ) ABP. ${ }^{10)} \mathrm{WCH}$ is defined as an OBP of $140 / 90 \mathrm{mmHg}$ or greater with a mean daytime ABP of $<135 / 85 \mathrm{mmHg}$ and sustained NT as an OBP of $<140 / 90 \mathrm{mmHg}$ together with an average HBP of $<135 / 85$ mmHg. ${ }^{10)}$ The prevalences of smoking, excess weight (overweight and obesity), hyperbetalipoproteinemia, hypertriglyceridemia, dyslipidemia, IGT, DM, WCH, HT, and CHD were determined for each decade, and the prevalences were compared between the decades. The comparison of proportions method was 
used in the statistical analyses.

\section{Results}

The study included 1068 cases (628 females and 440 males). The characteristics of the study patients are presented in Table I. Due to the small number of cases in the ninth decade (only 20 cases), they were not included in the statistical comparisons. The prevalence of smoking showed a significant increase from the third to the fourth decade $(11.0 \%$ versus $32.4 \%, P<0.001)$, following which it remained almost stable at between $25 \%$ and $30 \%$. As there were only $19(1.7 \%)$ underweight cases and $307(28.7 \%)$ normal weight cases, the prevalence of cases 20 years old or more with excess weight, $69.4 \%$ (742), was very high. The prevalence of excess weight increased gradually from $28.7 \%$ in the third decade to $87.0 \%$ in the seventh decade $(P<0.05$ in most steps), and then decreased to $78.5 \%$ in the eighth decade $(P<0.05)$ and to $60.0 \%$ in the ninth decade of life. Interestingly, the prevalence of excess weight showed its most significant increase from the third to fourth decades $(28.7 \%$ versus $63.6 \%, t$-test value: 9.64 ,

Table I. Characteristics of the Study Cases

\begin{tabular}{|c|c|c|c|c|c|c|c|c|c|c|c|}
\hline Variable & $\begin{array}{l}\text { Third } \\
\text { decade }\end{array}$ & $P$ & $\begin{array}{l}\text { Fourth } \\
\text { decade }\end{array}$ & $P$ & $\begin{array}{l}\text { Fifth } \\
\text { decade }\end{array}$ & $P$ & $\begin{array}{c}\text { Sixth } \\
\text { decade }\end{array}$ & $P$ & $\begin{array}{c}\text { Seventh } \\
\text { decade }\end{array}$ & $P$ & $\begin{array}{l}\text { Eighth } \\
\text { decade }\end{array}$ \\
\hline Number & 181 & & 157 & & 246 & & 249 & & 108 & & 107 \\
\hline Prevalence of smoking & $\begin{array}{c}11.0 \% \\
(20)\end{array}$ & $* * *$ & $\begin{array}{c}32.4 \% \\
(51)\end{array}$ & $\mathrm{ns} \dagger$ & $\begin{array}{c}28.8 \% \\
(71)\end{array}$ & ns & $\begin{array}{c}31.7 \% \\
(79)\end{array}$ & ns & $\begin{array}{c}23.1 \% \\
(25)\end{array}$ & ns & $\begin{array}{c}23.3 \% \\
(25)\end{array}$ \\
\hline Prevalence of excess weight & $\begin{array}{c}28.7 \% \\
(52)\end{array}$ & $* * *$ & $\begin{array}{c}63.6 \% \\
(100)\end{array}$ & $* * *$ & $\begin{array}{l}78.4 \% \\
(193)\end{array}$ & ns & $\begin{array}{l}83.1 \% \\
(207)\end{array}$ & ns & $\begin{array}{c}87.0 \% \\
(94)\end{array}$ & $*$ & $\begin{array}{c}78.5 \% \\
(84)\end{array}$ \\
\hline Prevalence of hyperbetalipoproteinemia & $\begin{array}{c}1.6 \% \\
(3)\end{array}$ & $* * *$ & $\begin{array}{c}12.7 \% \\
(20)\end{array}$ & ns & $\begin{array}{c}15.8 \% \\
(39)\end{array}$ & ns & $\begin{array}{c}19.6 \% \\
(49)\end{array}$ & ns & $\begin{array}{c}23.1 \% \\
(25)\end{array}$ & $*$ & $\begin{array}{c}14.0 \% \\
(15)\end{array}$ \\
\hline Prevalence of hypertriglyceridemia & $\begin{array}{c}5.5 \% \\
(10)\end{array}$ & $* * *$ & $\begin{array}{c}15.2 \% \\
(24)\end{array}$ & * & $\begin{array}{c}20.3 \% \\
(50)\end{array}$ & * & $\begin{array}{c}25.7 \% \\
(64)\end{array}$ & ns & $\begin{array}{c}24.0 \% \\
(26)\end{array}$ & $* *$ & $\begin{array}{c}11.2 \% \\
(12)\end{array}$ \\
\hline Prevalence of dyslipidemia & $\begin{array}{l}6.6 \% \\
(12)\end{array}$ & $* * *$ & $\begin{array}{c}26.7 \% \\
(42)\end{array}$ & ns & $\begin{array}{c}31.7 \% \\
(78)\end{array}$ & * & $\begin{array}{c}38.9 \% \\
(97)\end{array}$ & ns & $\begin{array}{c}39.8 \% \\
(43)\end{array}$ & $* * *$ & $\begin{array}{c}20.5 \% \\
(22)\end{array}$ \\
\hline Prevalence of IGT $\ddagger$ & $\begin{array}{l}0.5 \% \\
(1)\end{array}$ & ns & $\begin{array}{l}1.2 \% \\
(2)\end{array}$ & $* * *$ & $\begin{array}{c}10.1 \% \\
(25)\end{array}$ & $* * *$ & $\begin{array}{c}19.6 \% \\
(49)\end{array}$ & ns & $\begin{array}{c}21.2 \% \\
(23)\end{array}$ & ns & $\begin{array}{c}15.8 \% \\
(17)\end{array}$ \\
\hline Prevalence of diabetes mellitus & $\begin{array}{l}0.5 \% \\
(1)\end{array}$ & ns & $\begin{array}{l}1.9 \% \\
(3)\end{array}$ & $* * *$ & $\begin{array}{c}11.7 \% \\
(29)\end{array}$ & $* * *$ & $\begin{array}{c}21.6 \% \\
(54)\end{array}$ & ns & $\begin{array}{c}25.0 \% \\
(27)\end{array}$ & ns & $\begin{array}{c}26.1 \% \\
(28)\end{array}$ \\
\hline Prevalence of white coat hypertension & $\begin{array}{c}23.2 \% \\
(42)\end{array}$ & ns & $\begin{array}{c}24.2 \% \\
(38)\end{array}$ & $* *$ & $\begin{array}{c}33.3 \% \\
(82)\end{array}$ & $* * *$ & $\begin{array}{c}44.5 \% \\
(111)\end{array}$ & ns & $\begin{array}{c}40.7 \% \\
(44)\end{array}$ & $* *$ & $\begin{array}{c}25.2 \% \\
(27)\end{array}$ \\
\hline Prevalence of hypertension & $0.0 \%$ & $* *$ & $\begin{array}{c}5.0 \% \\
(8)\end{array}$ & $* * *$ & $\begin{array}{c}10.4 \% \\
(26)\end{array}$ & $* * *$ & $\begin{array}{c}20.4 \% \\
(51)\end{array}$ & $* *$ & $\begin{array}{c}31.4 \% \\
(34)\end{array}$ & ns & $\begin{array}{c}38.3 \% \\
(41)\end{array}$ \\
\hline Prevalence of $\mathrm{CHD} \S$ & $0.0 \%$ & ns & $0.0 \%$ & * & $\begin{array}{c}3.6 \% \\
(9)\end{array}$ & $* * *$ & $\begin{array}{c}12.8 \% \\
(32)\end{array}$ & $* *$ & $\begin{array}{c}22.2 \% \\
(24)\end{array}$ & ns & $\begin{array}{c}24.2 \% \\
(26)\end{array}$ \\
\hline
\end{tabular}

$* P<0.05 * * P<0.01 * * * P<0.001 \quad \dagger$ Nonsignificant $(P>0.05) \quad+$ Impaired glucose tolerance $\S$ Coronary heart disease 
Table II. Mean Blood Pressure Values of the Study Cases

\begin{tabular}{lccc}
\hline Variable & Sustained normotension $(n=551)$ & WCH* $^{*}(n=349)$ & Hypertension $(n=168)$ \\
\hline Prevalence & $51.5 \%$ & $32.6 \%$ & $15.7 \%$ \\
Mean age and range (year) & $38.8 \pm 12.3(15-83)$ & $48.2 \pm 11.3(15-79)$ & $55.3 \pm 10.3(33-85)$ \\
Female ratio & $57.1 \%(315)$ & $63.3 \%(221)$ & $65.4 \%(110)$ \\
Mean OBP $\dagger$ & $117.3 \pm 4.7 / 78.3 \pm 5.1$ & $153.3 \pm 5.4 / 97.3 \pm 9.3$ & $167.5 \pm 5.6 / 108.3 \pm 5.7$ \\
Mean HBP $\dagger$ & $97.7 \pm 13.3 / 73.1 \pm 5.1$ & $121.1 \pm 5.5 / 74.1 \pm 5.3$ & $149.5 \pm 6.3 / 97.3 \pm 7.3$ \\
Mean ABP§ & Not performed & $123.7 \pm 5.3 / 77.1 \pm 5.3$ & $150.7 \pm 7.7 / 98.7 \pm 7.3$ \\
Mean heart rate (beats/minute) & $65.1 \pm 11.5(52-129)$ & $75.3 \pm 13.3(61-149)$ & $80.5 \pm 11.3(63-167)$ \\
\hline
\end{tabular}

*White coat hypertension †Office blood pressure †Home blood pressure §24-hour ambulatory blood pressure monitoring

$P<0.001$ ), a pattern that was similar to that for smoking. The most significant finding of our study was that the prevalences of hyperbetalipoproteinemia, hypertriglyceridemia, dyslipidemia, IGT, and WCH increased significantly until the seventh decade and then decreased significantly, which was similar to that for excess weight $(P<0.05$ in most steps $)$. On the other hand, the prevalences of HT, $\mathrm{DM}$, and CHD always increased significantly with age and did not decrease $(P<$ 0.05 in most steps), indicating the increases were irreversible as opposed to the reversible patterns of excess weight, hyperbetalipoproteinemia, hypertriglyceridemia, dyslipidemia, IGT, and WCH. On the other hand, 517 cases with $\mathrm{WCH}$ and HT were diagnosed based on both HBP and ABP, and no difference was observed between the two methods according to the total number of cases diagnosed. Mean systolic/diastolic OBP, HBP, and ABP values and mean heart rates of the groups are summarized in Table II.

\section{Discussion}

Metabolic syndrome is a collection of metabolic risk factors for many terminal diseases. Although there is no universally accepted definition for the syndrome, it basically includes 5 features: obesity (high body weight, BMI, or waist circumference), high glucose and insulin levels, low HDL-C, high TG, and high BP. ${ }^{11)}$ However, the currently used definitions of a BP of $135 / 85$ or $140 / 90 \mathrm{mmHg}$ or above and a FPG of 100 or $110 \mathrm{mg} / \mathrm{dL}$ or above also include patients with DM and HT. In actual fact, the syndrome is a collection of risk factors rather than a final disease or diseases, and the condition is reversible with appropriate nonpharmaceutical approaches. On the other hand, HT, DM, and symptomatic atherosclerosis are irreversible and final states that almost always require drug therapy to delay complications. For example, in our study, the prevalences of hyperbetalipoproteinemia, hypertriglyceridemia, dyslipidemia, IGT, and WCH 
increased significantly in parallel to excess weight until the seventh decade and then subsequently decreased $(P<0.05$ in most steps). On the other hand, the prevalences of HT, DM, and CHD always continued to increase with age without any decrease $(P<0.05$ in most steps), indicating they were irreversible conditions. Therefore, metabolic syndrome alone is a disadvantageous but reversible condition and not a final disease, and after the development of one of the final metabolic diseases, the term metabolic syndrome probably loses most of its significance since from that point on the nonpharmaceutical approaches will provide little benefit to prevent development of the others, most likely due to the cumulative effects of the risk factors on organ systems over a long period of time. Thus, the definition of metabolic syndrome should include reversible metabolic risk factors such as excess weight (overweight and obesity), hyperbetalipoproteinemia, hypertriglyceridemia, dyslipidemia, IGT, and $\mathrm{WCH}$, but not HT, DM, CHD, and stroke-like terminal diseases.

Several authors reported that $\mathrm{WCH}$ is associated with some features of metabolic syndrome, ${ }^{12)}$ and more than $85 \%$ of cases with metabolic syndrome have elevated BP levels. ${ }^{4)}$ On the other hand, we observed very high prevalences of $\mathrm{WCH}$ even in younger subjects in the early decades of life; $23.2 \%$ in the third decade and $24.2 \%$ in the fourth decade. The high prevalences of WCH in society were also shown in other studies. ${ }^{13-15)}$ When we compared the sustained NT, WCH, and HT groups in another study, ${ }^{16}$ the prevalences of nearly all of the health problems including obesity, IGT, DM, and CHD showed significant progression from the sustained NT group towards the $\mathrm{WCH}$ and $\mathrm{HT}$ groups, with the WCH group being found to be an intermediate step in between. It is interesting that the prevalence of dyslipidemia was the highest in the $\mathrm{WCH}$ group; $41.6 \%$ versus $19.6 \%(P<0.001)$ in the sustained NT group and $35.5 \%$ in the HT group $(P<0.05){ }^{16)}$ Similar results indicating the higher prevalences of dyslipidemia in WCH cases were also observed in one of our previous studies, ${ }^{17)}$ which is in direct contrast to another study indicating serum TG and cholesterol levels did not differ significantly between NT, WCH, and sustained HT cases in males. ${ }^{18)}$ The relatively lower prevalence of dyslipidemia in the HT group may be explained by the already increased amount of adipose tissue per taken fat in the HT cases, since the prevalence of obesity was significantly higher in the HT group than in the $\mathrm{WCH}$ group $(P<0.01){ }^{16)}$ Therefore, the detected higher prevalences of WCH even in early decades, despite the lower prevalences of excess weight in these age groups, may indicate a trend towards weight gain and many final diseases. Most if not all of these relationships are closely related with the metabolic syndrome since $\mathrm{WCH}$ and dyslipidemia are two significant components of the syndrome, at least according to our opinion. On the other hand, we accept $\mathrm{WCH}$ as a different entity from borderline/mild HT due to the completely normal HBP and ABP values of 
WCH, whereas they are abnormal in mild HT cases. However, both kinds of patients can benefit from lifestyle modification including exercise, weight loss, and a diet low in animal products and high in fresh fruits and vegetables.

It is already known that excess weight leads to both structural and functional abnormalities in many systems of the body, as well as a higher risk of death from all causes, including cardiovascular diseases and cancers, and increases parallel to the range of moderate to severe weight excess in all age groups ${ }^{19)}$ The effects of body weight on BP were also demonstrated previously by us when we found that the prevalence of sustained NT was significantly higher in underweight cases (80.3\%) than normal weight (64.0\%) and overweight cases $(31.5 \%)^{20)}(P<0.05$ for both), and in another study that $55.1 \%$ of cases with HT were obese compared to $26.6 \%$ of cases with NT $(P<0.001) .{ }^{21)}$ Thus, the dominant underlying risk factor of the metabolic syndrome appears to be already existing excess weight $\left.{ }^{4}\right)$ or a trend towards excess weight, which is probably the main cause of insulin resistance, dyslipidemia, IGT, and WCH. Even prevention of the accelerating trend of body weight with diet or exercise, even in the absence of prominent weight loss, will probably result with resolution of many parameters of the metabolic syndrome. ${ }^{22-24)}$ However, it is our opinion that limitation of excess weight as excessive fat tissue in and around the abdomen under the heading of abdominal obesity is meaningless, and instead should be defined as excess weight including overweight and obesity via BMI, since adipocytes function as an endocrine organ that produces a variety of cytokines and hormones anywhere in the body. ${ }^{4)}$ The resulting hyperactivity of the sympathetic nervous system and renin-angiotensin-aldosterone system is most likely associated with insulin resistance, endothelial dysfunction, and elevated BP. Similarly, the Adult Treatment Panel III reported ${ }^{9)}$ that although some people are classified as overweight due to a large muscular mass, most of them also have excess fat tissue, and being overweight and obese do not only predispose a person to CHD, stroke, and numerous other conditions, they also have a high burden of other CHD risk factors including type 2 DM, HT, and dyslipidemia.

In conclusion, metabolic syndrome is a reversible progression step between physical health and irreversible final diseases terminating with increased mortality and disabilities. Thus, the definition of metabolic syndrome should include reversible metabolic risk factors such as excess weight (overweight and obesity), hyperbetalipoproteinemia, hypertriglyceridemia, dyslipidemia, IGT, and $\mathrm{WCH}$, instead of irrevesible diseases such as DM, HT, CHD, and stroke that have already developed and require drug therapy. After development of one of the final metabolic diseases, the term metabolic syndrome probably loses most of its significance, since from now on, nonpharmaceutical approaches such as lifestyle changes, diet, and exercise will provide little benefit to prevent development of 
the others, most likely due to the cumulative effects of the risk factors on body systems over a long period of time.

\section{REFERENCES}

1. Eckel RH, Grundy SM, Zimmet PZ. The metabolic syndrome. Lancet 2005; 365: 1415-28. (Review)

2. Grundy SM, Brewer HB Jr, Cleeman JI, Smith SC Jr, Lenfant C. Definition of metabolic syndrome: Report of the National Heart, Lung, and Blood Institute/American Heart Association conference on scientific issues related to definition. Circulation 2004; 109: 433-8. (Review)

3. Tonkin AM. The metabolic syndrome(s)? Curr Atheroscler Rep 2004; 6: 165-6.

4. Franklin SS, Barboza MG, Pio JR, Wong ND. Blood pressure categories, hypertensive subtypes, and the metabolic syndrome. J Hypertens 2006; 24: 2009-16.

5. Clark LT, El-Atat F. Metabolic Syndrome in African Americans: implications for preventing coronary heart disease. Clin Cardiol 2007; 30: 161-4. (Review)

6. Ohkubo T, Asayama K, Kikuya M, et al. How many times should blood pressure be measured at home for better prediction of stroke risk? Ten-year follow-up results from the Ohasama study. J Hypertens 2004; 22: 1099104.

7. Nakashima T, Yamano S, Sasaki R, et al. White-coat hypertension contributes to the presence of carotid arteriosclerosis. Hypertens Res 2004; 27: 739-45.

8. Curgunlu A, Karter Y, Uzun H, et al. Hyperhomocysteinemia: an additional risk factor in white coat hypertension. Int Heart J 2005; 46: 245-54.

9. National Cholesterol Education Program (NCEP) Expert Panel on Detection, Evaluation, and Treatment of High Blood Cholesterol in Adults (Adult Treatment Panel III). Third Report of the National Cholesterol Education Program (NCEP) Expert Panel on Detection, Evaluation, and Treatment of High Blood Cholesterol in Adults (Adult Treatment Panel III) final report. Circulation 2002; 17: 106: 3143-421.

10. O’Brien E, Asmar R, Beilin L, et al; European Society of Hypertension Working Group on Blood Pressure Monitoring. European Society of Hypertension recommendations for conventional, ambulatory and home blood pressure measurement. J Hypertens 2003; 21: 821-48. (Review)

11. Hunt KJ, Resendez RG, Williams K, Haffner SM, Stern MP; San Antonio Heart Study. National Cholesterol Education Program versus World Health Organization metabolic syndrome in relation to all-cause and cardiovascular mortality in the San Antonio Heart Study. Circulation 2004; 110: 1251-7.

12. Mulè G, Nardi E, Cottone S, et al. Metabolic syndrome in subjects with white-coat hypertension: impact on left ventricular structure and function. J Hum Hypertens 2007; 21: 854-60.

13. Helvaci MR, Seyhanli M. What a high prevalence of white coat hypertension in society! Intern Med 2006; 45 : 671-4.

14. Hozawa A, Ohkubo T, Kikuya M, et al. Blood pressure control assessed by home, ambulatory and conventional blood pressure measurements in the Japanese general population: the Ohasama study. Hypertens Res 2002; 25: 57-63.

15. Celis H, Fagard RH. White-coat hypertension: a clinical review. Eur J Intern Med 2004; 15: 348-57.

16. Helvaci MR, Kaya H, Duru M, Yalcin A. What is the relationship between white coat hypertension and dyslipidemia? Int Heart J 2008; 49: 87-93.

17. Helvaci MR, Kaya H, Seyhanli M, Cosar E. White coat hypertension is associated with a greater all-cause mortality. J Health Sci 2007; 53: 156-60.

18. Björklund K, Lind L, Vessby B, Andrén B, Lithell H. Different metabolic predictors of white-coat and sustained hypertension over a 20 -year follow-up period: a population-based study of elderly men. Circulation 2002; 106: 63-8.

19. Calle EE, Thun MJ, Petrelli JM, Rodriguez C, Heath CW Jr. Body-mass index and mortality in a prospective cohort of U.S. adults. N Engl J Med 1999; 341: 1097-105.

20. Helvaci MR, Ozcura F, Kaya H, Yalcin A. Funduscopic examination has limited benefit for management of hypertension. Int Heart J 2007; 48: 187-94. 
21. Helvaci MR, Kaya H, Yalcin A, Kuvandik G. Prevalence of white coat hypertension in underweight and overweight subjects. Int Heart J 2007; 48: 605-13.

22. Azadbakht L, Mirmiran P, Esmaillzadeh A, Azizi T, Azizi F. Beneficial effects of a Dietary Approaches to Stop Hypertension eating plan on features of the metabolic syndrome. Diabetes Care 2005; 28: 2823-31.

23. Volek JS, Feinman RD. Carbohydrate restriction improves the features of Metabolic Syndrome. Metabolic Syndrome may be defined by the response to carbohydrate restriction. Nutr Metab (Lond) 2005; 2: 31 .

24. Helvaci MR, Kaya H, Borazan A, Ozer C, Seyhanli M, Yalcin A. Metformin and parameters of physical health. Intern Med 2008; 47: 697-703. 